\title{
ANÁLISE JURÍDICĀ DOS IMPACTOS SOCIOAMBIENTAIS E URBANOS DAS OBRAS DE MACRODRENAGEM: IGARAPÉ CAXANGÁ EM BOA VISTA, RORAIMA
}



\section{RESUMO}

O presente artigo científico, por meio de análise crítica, da pesquisa bibliográfica e da visitação in loco, tem como objetivo traçar, prima facie, generalidades sobre a macrodrenagem, sua definição, consequências, a necessidade de licenciamento ambiental para este tipo de empreendimento que é considerado potencialmente poluidor em face de suas características e alcance, mormente sobre as que atingem, direta ou indiretamente o igarapé Caxangá, localizado na parte central de Boa Vista, capital do estado amazônico de Roraima. Disserta-se, ainda, sobre as responsabilidades previstas no ordenamento jurídico-ambiental brasileiro comuns ao poder público e às empresas contratadas quando do cometimento de infrações, sobretudo em relação as implicações urbanas e os subsequentes efeitos ambientais e sociais que estão correlacionados com o princípio constitucional do desenvolvimento sustentável. Desta forma, é preciso compreender esta dinâmica da construção da produção e reprodução do espaço urbano frente as premissas cogentes, tendo em conta bases históricas dos problemas de obras do gênero e repercussão antrópicas até a integração no sistema de macrodrenagem pertencente ao projeto do Parque do Rio Branco. Indispensável é, entretanto, fomentar mecanismos legais que possam, de algum modo, propiciar condições para validar o direito humano fundamental de todos à sadia qualidade de vida (art. 225, caput, da Constituição da República Federativa do Brasil).

Palavras - chave: Macrodrenagem. Igarapé Caxangá. Licenciamento. Responsabilidade. Desenvolvimento Sustentável. Implicações.
RESUMEN

El presente artículo científico, por medio de análisis crítico, de la investigación bibliográfica y de la visitación in loco, tiene como objetivo trazar, prima facie, generalidades sobre el macrodrenaje, su definición, consecuencias, la necesidad de licenciamiento ambiental para este tipo de emprendimiento que es que se considera potencialmente contaminante frente a sus características y alcance, principalmente sobre las que alcanzan, directa o indirectamente el igarapé Caxangá, ubicado en la parte central de Boa Vista, capital del estado amazónico de Roraima. Se discutía, además, sobre las responsabilidades previstas en el ordenamiento jurídico-ambiental brasileño comunes al poder público ya las empresas contratadas cuando de la comisión de infracciones, sobre todo en relación a las implicaciones urbanas y los subsecuentes efectos ambientales y sociales que están correlacionados con el principio constitucional del desarrollo sostenible. De esta forma, es necesario comprender esta dinámica de la construcción de la producción y reproducción del espacio urbano frente a las premisas que se plantean, teniendo en cuenta bases históricas de los problemas de obras del género y repercusión antrópica hasta la integración en el sistema de macrodrenaje perteneciente al proyecto del Parque del Río blanco. Sin embargo, indispensable es fomentar mecanismos legales que puedan, de algún modo, propiciar condiciones para validar el derecho humano fundamental de todos a la sana calidad de vida (art. 225, caput, de la Constitución de la República Federativa del Brasil). Palabras clave: Macrodrenaje. Igarapé Caxangá. La concesión de Licencias. Responsabilidad. Desenvolvimiento Sustentable. Implicaciones. 


\section{INTRODUÇÃO}

A expansão dos centros urbanos brasileiros é acompanhada de muitos desafios socioambientais, dentre os quais estão os direitos básicos do cidadão à moradia e ao saneamento, considerados trincheiras para o desenvolvimento sustentável. A razão desta assertiva está alicerçada na constatação da célere transformação evidenciada nestes espaços diretamente propiciada pela concentração populacional, alinhado à ineficiência das políticas públicas em nível federal, estadual ou municipal.

Em face disto, soluções de engenharia urbanística surgem para aliviar gargalos de infraestrutura das grandes, médias e pequenas cidades. Todavia, nem sempre estas estratégias coadunam com os principios e diretrizes traçadas pela Política Nacional do Meio Ambiente, Lei no 6.938 de 1981, e os preceitos de ordem constitucional ambiental (art. 225) que indica o meio ambiente como direito humano fundamental e essencial à sadia qualidade de vida. Imperioso, outrossim, é valer-se das regras jurídicas aplicáveis à regularização de empreendimentos do gênero pela via do licenciamento ambiental e das nuances sancionatórias estabelecidas na ordem legal vigente.

Neste artigo científico, o objeto principal é avaliar a influência das obras de macrodrenagem realizadas no Igarapé Caxangá na produção e reprodução do espaço urbano e seu paralelo com problemas socioambientais e descumprimento de obrigações legais e constitucionais, as quais deveriam garantir, efetivamente, a promoção do desenvolvimento sustentável. Referido curso d'água está localizado no bairro central do município amazônico Boa Vista, Estado de Roraima, que integra a configuração geopolítica cuja terminologia é Amazônia Legal, juntamente com os estados do Acre, Pará, Amazonas, Rondônia, Amapá,
Mato Grosso e as regiões ao norte do paralelo $13^{\circ} \mathrm{S}$ de Tocantins e Goiás e oeste do meridiano de $44^{\circ} \mathrm{W}$ do Maranhão (BRASIL. Lei 12.651, 2012, art. 3ㅇ, I), numa área total aproximada de

$5.020 .000 \mathrm{~km}^{2}$ ou $58,95 \%$ do território brasileiro (IBGE, 2018).

A capital de Roraima está localizada na Amazônia Setentrional e inserida no Pediplano Rio Branco, cuja superficie se estende até a serra de Pacaraima ao Norte, vindo a compreender uma área extensamente plana, algumas vezes interrompida por pequenas ondulações e depressões incipientes, por onde meandram igarapés, intermitentes ou não, marcados por alinhamento de veredas de buritis e inúmeras lagoas fechadas ou parcialmente drenadas (SCHAEFER, 1994; VALE JÚNIOR, 2000; VALE JÚNIOR, SOUSA, NASCIMENTO, 2014).

A historicidade e seu contexto alusivo ao mencionado curso d'água, seja quanto ao passado e presente, com suas graves consequências socioambientais, não pode olvidar de eventuais implicações acerca deste recurso natural para o futuro da proteção ambiental nesta área.

As obras de canalização que representam parte de sistema de macrodrenagem existente e afeta diretamente o comentado igarapé, ademais, estão incluídas no projeto municipal de construção do empreendimento denominado Parque do Rio Branco que se constituem em elementos deveras importante nesta dinâmica urbana, social e ambiental.

Para tanto, o processo formal e sistemático utilizado no desenvolvimento deste trabalho envolveu o método científico dedutivo aplicado para analisar, demonstrar e justificar o objeto proposto por meio de recursos lógico-discursivos e levantamento de dados técnico-científicos de fontes bibliográficas acerca do tema e das normas jurídicas aplicáveis. o racionalismo crítico, ademais, propiciou meios para arregimentar uma avaliação deste quadro e seus nefastos resultados.

\section{DISCUSSÃO}




\section{A MACRODRENAGEM COMO MEIO DE INTEGRAÇÃO URBANA DE COR- REDORES NATURAIS DE ÁGUAS}

\section{GENERALIDADES}

O sistema de drenagem é compreendido como um conjunto de obras de infraestrutura urbana destinado à realização de coleta, transporte e lançamento final de águas superficiais.

Nada mais é que uma série de medidas que visam a minimizar os riscos a que estão expostas as populações em decorrência de eventuais ou constantes inundações para possibilitar um desenvolvimento urbano harmônico, articulado e, principalmente, ambientalmente sustentável.

Referido sistema é comumente dividido em duas categorias: Microdrenagem e Macrodrenagem.

A microdrenagem é formada pelas redes coletoras de águas pluviais (poços de visita, sarjetas, bocas-de-lobo e meios-fios), conjunto de condutos pluviais presentes nos loteamentos ou na rede primária urbana. São estruturas que conduzem as águas do escoamento superficial para as galerias ou canais urbanos para lidar com precipitações de risco moderado.

Por sua vez, a macrodrenagem abrange diversos sistemas de microdrenagem a fim de suportar precipitações de maior risco de acordo com as circunstâncias socioambientais do local.

Como afirmado, a drenagem tem por finalidade a prevenção de danos e a minimização de riscos gerados principalmente por enchentes ou inundações. Estas ocorrem especialmente pela ocupação indevida de populações em áreas de risco e pela urbanização, responsável pela redução significativa da permeabilidade do solo e, consequentemente, pelo aumento da velocidade de escoamento superficial e a redução de recarga dos lençóis freáticos.

Do mesmo modo, a implementação desorganizada de um sistema de drenagem pode levar a graves consequências ambientais e socioeconômicas como ao aumento das velocidades de escoamento e consequente transferência de inundação para a jusante ; à eliminação de ecossistemas aquáticos; a processos erosivos nas margens dos cursos d'água e a elevados custos para o município, sem, necessariamente, obter resultados efetivos.

Durante anos, a estratégia utilizada quando da execução de drenagens esteve voltada à retificação de cursos de água e ao revestimento de suas calhas. Atualmente, porém, busca-se a despoluição dos corredores de água e a manutenção das várzeas de inundação, de forma a dispensar obras estruturantes, reduzir custos e problemas gerados pelas mesmas, aproveitando-se o potencial urbanístico que as áreas verdes e parques lineares podem gerar.

Partindo dessa perspectiva é que a análise jurídica dos itens seguintes será feita, de modo que a substituir o binômio prevenção-integração pelo binômio prevenção-preservação.

\section{LICENCIAMENTO AMBIENTAL PARA OBRAS DE CANALIZAÇÃO FLUVIAL}

Inexiste direito subjetivo à livre utilização dos recursos naturais, uma vez que o meio ambiente é qualificado como patrimônio de uso coletivo. Devido a isso, faz-se necessário o consentimento estatal, o que se dá por meio do licenciamento ambiental, instrumento de gestão ambiental que busca a implementação dos princípios do desenvolvimento sustentável, da prevenção e da precaução.

Esta compreensão, anterior mesmo à Constituição Federal de 1988, é perceptível na

1 Ponto referencial a qual dirige-se o fluxo natural das águas, do local de maior altitude para o de menor altitude. 
Lei 6938/1981, em seu art. 9a-, IV, que relaciona o licenciamento ambiental como instrumento da Política Nacional de Meio Ambiente cuja definição, por sua vez, está prevista no art. 2ä, I, da Lei Complementar 140/2011, in verbis:

[...] procedimento administrativo destinado a licenciar atividades ou empreendimentos utilizadores de recursos ambientais, efetiva ou potencialmente poluidores ou capazes, sob qualquer forma, de causar degradação ambiental.

Nesse contexto, a construção de obras de infraestrutura destinadas à Macrodrenagem não escapa à necessidade do referido licenciamento, de forma prévia inclusive, como nítido no art. 3-, III Resolução 005/1988 e no art. 2a , caput, e anexo I da Resolução 237/1997, ambas do Conselho Nacional do Meio Ambiente:

Res. 005/1988, Art. 30 - Ficam sujeitas a licenciamento as obras de sistemas de abastecimento de água sistemas de esgotos sanitários, sistemas de drenagem e sistemas de limpeza urbana a seguir especificadas:

$$
\text { [...] }
$$

III - Em Sistemas de Drenagem:

a) obras de lançamento de efluentes de sistemas de microdrenagem;

b) obras de canais, dragagem e retificação em sistemas de macrodrenagem.

Res. 237/1997, art. 2o - A localização, construção, instalação, ampliação, modificação e operação de empreendimentos e atividades utilizadoras de recursos ambientais consideradas efetiva ou potencialmente poluidoras, bem como os empreendimentos capazes, sob qualquer forma, de causar degradação ambiental, dependerão de prévio licenciamento do órgão ambiental competente, sem prejuízo de outras licenças legalmente exigíveis (grifo nosso)

$$
\text { [...] }
$$

Anexo 1 - Atividades ou empreendimentos sujeitos ao Licenciamento Ambiental Obras Civis

$$
\text { - Canais para Drenagem. }
$$

\footnotetext{
2 Conforme extrato de contrato que prevê o Termo de Compromisso no 065/2016/Ministério da Integra-
} ção. Disponível no Diário Oficial da União de 29 de dezembro de 2017.
Sendo um procedimento administrativo, o licenciamento ambiental é um conjunto de atos que deve obedecer às etapas previstas no art. 10 da Resolução do Conselho Nacional do Meio Ambiente (CONAMA) no 237/97, norma que prevê o procedimento e critérios utilizados em tal instrumento.

Dentro desse conjunto de atos, destaca-se a imprescindibilidade de estudos ambientais que devem ser realizados para subsidiar a análise da licença requerida. Conforme o inciso I da norma sob análise, cabe ao órgão ambiental competente, com a participação do empreendedor, definir qual o estudo ambiental pertinente ao empreendimento desejado.

Porém, em se tratando de instalação de obra ou atividade potencialmente causadora de significativa degradação do meio ambiente, na forma do art. 225, §1ä, IV, da Constituição Federal de 1988, há obrigatoriedade de Estudo Prévio de Impacto Ambiental (EIA) e Relatório de Impacto Ambiental (RIMA).

Ademais, em se tratando de obra pública receptora de recursos do Ministério da Integração ${ }^{2}$, a instituição financeira que liberou e liberará valores deveria, obrigatoriamente, atuar em conformidade com a redação do art. 12 da Lei de Política Nacional do Meio Ambiente, condicionando quaisquer repasses a regularidade do procedimento do licenciamento ambiental e, criteriosamente, ao cumprimento das normas, critérios e padrões expedidos pelo CONAMA.

Em face das implicações cogentes quanto a forma com que recursos públicos deveriam ser utilizados, especialmente quando há alteração da qualidade ambiental (art. 3으 da Lei no 6.938/1981), deveria ser exigido previsão nos projetos técnicos da realização de obras e aquisição de equipamentos destinados ao controle de degradação ambiental e que pudessem redundar na melhoria da qualidade do meio ambiente. Estas inserções, ex vi legis, não são opções a cargo do financiador e muito menos do município de Boa Vista que é o gestor dos repasses no interesse da coleti- 
vidade, seja ou não diretamente afetada pelo empreendimento.

Também constituem atos de grande relevância ambiental dentro do contexto da macrodrenagem a emissão de Certidão da Prefeitura Municipal, cuja finalidade é declarar que o local e o tipo de empreendimento ou atividade adequam-se à regulamentação do uso e ocupação do solo local, e a autorização para supressão de vegetação, uma vez que as áreas periféricas aos igarapés de Boa Vista (em uma variação de $50 \mathrm{~m}$ a $100 \mathrm{~m}$ ) são áreas de preservação ambientais (APA's).

Após a conclusão de todas as etapas do art. 10 da Resolução 237/97, a Administração Pública expedirá licença ambiental, ato administrativo pelo qual o órgão ambiental competente estabelece condições, restrições e medidas de controle ambiental que deverão ser obedecidas pelo empreendedor.

\section{A RESPONSABILIDADE CIVIL, ADMI- NISTRATIVA E PENAL ENTRE O PO- DER PÚBLICO E AS CONSTRUTORAS}

Em decorrência do princípio do Poluidor-Pagador (Princípio da Responsabilidade), todas as despesas e custos quanto à realização de estudos de impacto ambiental recairão sobre o proponente do projeto (empreendedor).

Dessa forma, às expensas do empreendedor, os estudos necessários ao processo de licenciamento ambiental serão necessariamente realizados por profissionais legalmente habilitados.

A responsabilidade pelo conteúdo dos estudos, do mesmo modo, recai sobre o empreendedor e sobre seus autores de forma que estão sujeitos à tríplice sanção: administrativa, civil e penal, todas autônomas entre si.

Tamanha a relevância do bem jurídico em questão (meio ambiente ecologicamente equilibrado), que a tríplice responsabilização encontra arcabouço na Constituição Federal, em seu art. 225, §3a.:

§ 30 As condutas e atividades consideradas lesivas ao meio ambiente sujeitarão os infratores, pessoas fisicas ou jurídicas, a sanções penais $e$ administrativas, independentemente da obrigação de reparar os danos causados (grifo nosso)

Apesar de 0 art. 225, caput, da Constituição Federal impor ao Estado (lato sensu) o dever de defender e preservar o meio ambiente, isso não impede que uma pessoa jurídica de direito público e as de direito privado prestadoras de serviços públicos (construtoras, na hipótese) no exercício de suas atribuições, eventualmente causem dano a tal bem de interesse difuso.

Para tais hipóteses, prevê o §6a do art. 37 da Carta Maior:

$\S 6$ o As pessoas jurídicas de direito público e as de direito privado prestadoras de serviços públicos responderão pelos danos que seus agentes, nessa qualidade, causarem a terceiros, assegurado o direito de regresso contra o responsável nos casos de dolo ou culpa.

Tais normas constitucionais, atreladas à definição de "poluidor" externada pela Lei 6938/1981, art. 3a , IV, torna inquestionável a possibilidade de responsabilização do Poder Público e da pessoa jurídica de direito privado prestadora de serviços públicos por danos ao meio ambiente: "poluidor, a pessoa física ou jurídica, de direito público ou privado, responsável, direta ou indiretamente, por atividade causadora de degradação ambiental". Estabelecida essa assertiva, passamos à análise de cada modalidade de sanção.

No que tange à responsabilidade civil, suficiente é a análise do art. 14, §1a, da Lei no 6938/1981 para verificar que a mesma é objetiva. 
[...] é o poluidor obrigado, independentemente da existência de culpa, a indenizar ou reparar os danos causados ao meio ambiente e a terceiros, afetados por sua atividade. O Ministério Público da União e dos Estados terá legitimidade para propor ação de responsabilidade civil e criminal, por danos causados ao meio ambiente (grifo nos-

so).

Assim, para surgir a obrigação de indenizar ou reparar os danos ambientais, basta a comprovação do dano e do nexo de causalidade. A responsabilidade civil é tida, ainda, pelo Superior Tribunal de Justiça como solidária e imprescritivel.

Por sua vez, quanto à responsabilidade penal, é indispensável a comprovação do elemento subjetivo da conduta, sendo imputável inclusive a pessoas jurídicas, na forma do art. 3 a da Lei 9.605/98, regulamentadora do §3a do art. 225 da Constituição Federal, no que tange a crimes ambientais (cuja ação penal é sempre pública incondicionada) e a infrações administrativas:

Art. 3o As pessoas jurídicas serão responsabilizadas administrativa, civil e penalmente conforme o disposto nesta Lei, nos casos em que a infração seja cometida por decisão de seu representante legal ou contratual, ou de seu órgão colegiado, no interesse ou beneficio da sua entidade. Parágrafo único. A responsabilidade das pessoas jurídicas não exclui a das pessoas físicas, autoras, co-autoras ou partícipes do mesmo fato.

Desta forma, para responsabilização penal de pessoas jurídicas, hipótese aceita inclusive pelo Superior Tribunal de Justiça e pelo Supremo Tribunal Federal, deve-se observar se o crime foi cometido no interesse ou beneficio da entidade e, outrossim, por decisão de representante legal, contratual ou órgão colegiado. Caso contrário, há inépcia da inicial e trancamento da ação proposta necessariamente pelo Ministério Público Estadual.

Nota-se, ainda, viável a responsabiliza- ção penal da pessoa jurídica independentemente da responsabilização simultânea de pessoa física, não havendo aplicação da teoria da dupla imputação conforme a jurisprudência dos tribunais superiores.

Por fim, destaca-se a responsabilidade administrativa, incidente em toda conduta comissiva ou omissiva que viole as regras jurídicas de relativas a uso, gozo, promoção, proteção e recuperação do meio ambiente.

Essa modalidade de responsabilidade não exige dano efetivo ao meio ambiente. Basta a infração à legislação administrativa ambiental, porém, diferentemente do que ocorre quanto à responsabilidade civil, é necessário comprovar a infração (responsabilidade subjetiva).

Nada obstante a abrangência dessa responsabilidade, em decorrência do princípio da legalidade é preciso que o ato esteja definido em lei ( lato sensu) como infração administrativa, cabendo, na hipótese, as sanções do art. 72 da Lei 9.605/98 e art. 3a do Decreto $6.514 / 08$, cuja aplicação constitui exercício do poder de polícia.

Tem-se que na obra de macrodrenagem sob análise, sendo constatado a existência de infração ambiental por qualquer funcionário dos órgãos ambientais integrantes do Sistema Nacional de Meio Ambiente (SISNAMA), com atribuição para atividades fiscalizadoras, é possível a lavratura de auto de infração ambiental e instauração de processo administrativo para averiguação dos requisitos específicos de cada responsabilização.

Afinal, nada obstante ser um empreendimento executado pela própria Prefeitura do Município de Boa Vista, por meio de pessoa jurídica de direito privado, é plenamente possível a responsabilização de ambas as pessoas jurídicas e até mesmo de pessoas físicas, partindo-se da interpretação conjunta de normas constitucionais e infraconstitucionais acima exposta. 


\section{O EXEMPLO LOCAL DO IGARAPÉ MIRANDINHA}

Tendo como pedra de toque a situação socioambiental pela qual passou e passa o Igarapé Mirandinha, é possivel ter-se uma noção dos impactos a que estão sujeitos o Igarapé Caxangá.

O processo de (des)construção da canalização do igarapé Mirandinha somado à ausência de conscientização ambiental por parte da comunidade ensejou o processo de destruição do mesmo e consequente desrespeito ao direito à sadia qualidade de vida da população local.

Conforme estudos locais ${ }^{3}$, os principais danos sofridos pelo igarapé foram: retirada da mata ciliar, altos índices de eutrofização em decorrência do despejo de esgoto in natura das residências ribeirinhas, perda significativa da capacidade de autodepuração e perda da rica fauna aquática do local.

A estes prejuízos de dificílima reparação também está sujeito o Igarapé Caxangá caso as atuais obras de Macrodrenagem restrinjam-se a integrar o curso d'água ao já superado ambiente antrópico, alheio à manutenção do equilíbrio ecológico.

\section{O IGARAPÉ CAXANGÁ}

\section{A URBANIZAÇÃO DO MUNICÍPIO DE BOA VISTA E OS HISTÓRICOS PRO- BLEMAS ANTRÓPICOS DA BACIA HI- DROGRÁFICA DO IGARAPÉ CAXAN- GÁ}

O espaço ao qual, atualmente, denominamos de Boa Vista transforma-se a passos largos. Com o galopar dos anos, passamos de latifúndio real para proteção de fronteira pátria à capital de ente federado.

Nas últimas décadas, o município esca-

$3 \quad$ Em especial os de Warner Velasque Ribeiro (2012) lou os degraus da concentração populacional de forma exponencial, em números, aduzem os autores Araújo e Tavares (2018, p. 37):

Nos últimos 30 anos, a cidade de Boa Vista no estado de Roraima passou por intenso processo de expansão urbana. Segundo dados do Instituto Brasileiro de Geografia e Estatística (IBGE, 2016), na década de 1980 o município contava com 67.017 habitantes. No ano de 2015, este quantitativo representa 320.714 habitantes, dos quais 277.799 habitantes viviam na zona urbana e 42.915 na zona rural, ou seja, $86,62 \%$ da população vivem no espaço urbano consolidado de Boa Vista.'

O acelerado processo de expansão da cidade, alinhado às ineficientes políticas públicas de Estado, resultaram em consequências normais a concentração desordenada de pessoas, em especial, no que tange a moradia e o saneamento básico, que são direitos constitucionalmente garantidos.

A peculiar geografia do território boavistense propiciou a ocupação de áreas improprias, como as margens de canais de águas, regionalmente denominados de igarapés. Diante disso, problemas reflexos a este tipo de assentamento irregular emergiram em nossa capital. Neste sentido, pontua Antônio Carlos (2015, p. 15):

O crescimento populacional fez com que áreas impróprias fossem ocupadas, principalmente áreas próximas a cursos d'água, as quais por constituírem planícies de inundação têm suas áreas comprimidas, impermeabilizadas, aterradas $e$ mata ciliar retirada, fatores estes que impedem o retrocesso das ações oriundas de inundações e agravam problemas relacionados a alagamentos.

Mercê do exposto, é possível compreender o processo de urbanização das margens do Igarapé Caxangá e suas trágicas consequências ao ambiente. Antemão, vale ressaltar 
que o Caxangá nasce da confluência entre os igarapés Tiririca e Jararaca, ademais, a importante bacia hidrográfica também recebe afluência do corredor d'água do Mecejana, os três riachos já completamente canalizados.

No entanto, precipuamente os problemas socioambientais do Igarapé Caxangá despontam-se a partir da margem direita da Av. Ville Roy (sentido centro), bairro São Vicente, até sua foz no bairro Caetano Filho.

O trecho citado do veio fluvial é margeado em toda sua extensão por uma população vulnerável e que historicamente sofre com os desequilíbrios antrópicos. Poluição, enchentes, deslizamentos de terra, doenças hídricas, são alguns dos inconvenientes promovidos pela destruição da mata ciliar, assentamento populacional irregular com despejo de esgoto no curso de água, e inexistência de políticas de saneamento básico eficazes.

\section{O PARQUE DO RIO BRANCO E A MA- CRODRENAGEM DO CAXANGÁ}

Com o objetivo de solucionar os problemas urbanísticos e ambientais que envolvem o Igarapé Caxangá e, sobretudo o embaraço social na qual se encontra o bairro Caetano Filho, região entregue ao tráfico ilícito de entorpecentes e sujeita, rotineiramente, a ocorrências de inundações em função da proximidade com o principal curso d'água que é o rio Branco, veio o município de Boa Vista a propor um ambicioso plano de revitalização do local, o qual altera radicalmente sua concepção original e estruturação ao longo do tempo.

O projeto de construção do Parque do Rio Branco, empreendimento este anunciado no pretérito ano e que englobará, ao término, a desapropriação de pelo menos 242 imóveis, tal como haverá necessidade de elevação da Av. Sebastião Diniz, bem como, segundo dados e informações do município: a canalização do córrego Caxangá; obras de macrodrenagem; ajuste do nível para prevenção de enchentes; instalação de equipamentos que promovam a atração do público e turística no local, marina flutuante, cortinas d'água, calçadão e espaço para construção de prédios administrativo.

Estima-se que o empreendimento público possa custar ao tesouro aproximadamente cem milhões de reais e seja entregue aos cidadãos em quatro anos. A primeira fase de obras de infraestrutura iniciou neste ano (2018), com a obra de macrodrenagem urbana do Igarapé Caxangá, pela qual toda a extensão do córrego será canalizada, etapa orçada em $\mathrm{R} \$$ 46.300.000,00 (quarenta e seis milhões e trezentos mil reais).

Os seguintes registros fotográficos bem indicam a extensão e potencial do empreendimento no local do fato, inclusive o desenvolvimento das obras financiadas com recursos do Ministério da Integração.

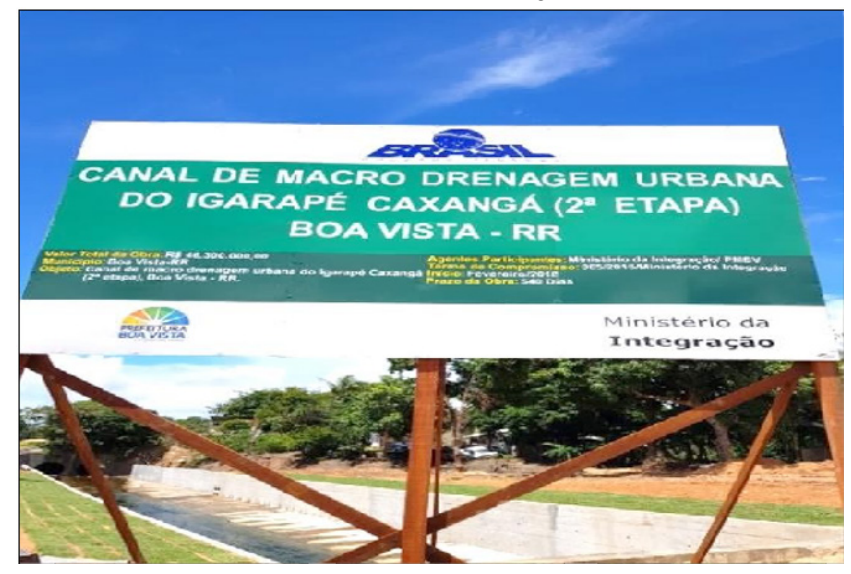

Figura 1. Placa de contrato de obra pública Fonte: Arquivo pessoal (2018).

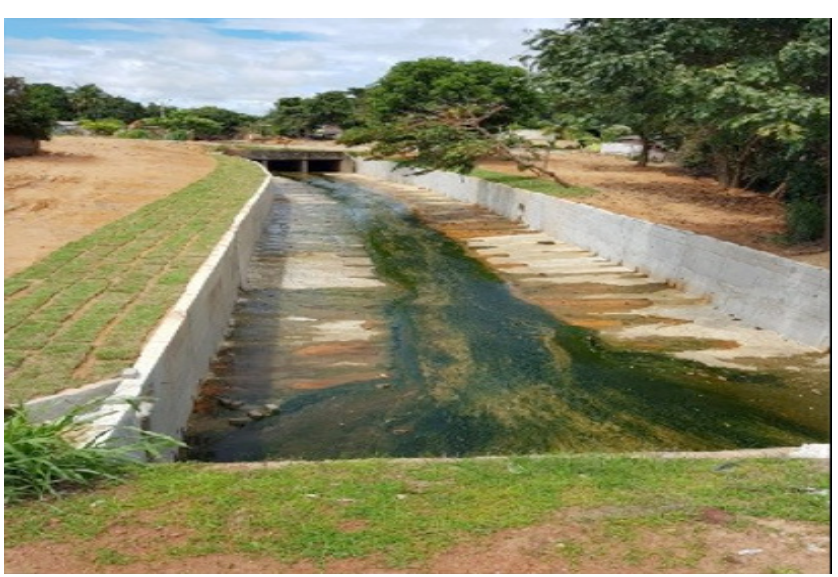

Figura 2. Trecho do Igarapé Caxangá entre a Av. Ville Roy e Av. Nossa Sra. da Consolata. Fonte: Arquivo pessoal (2018). 


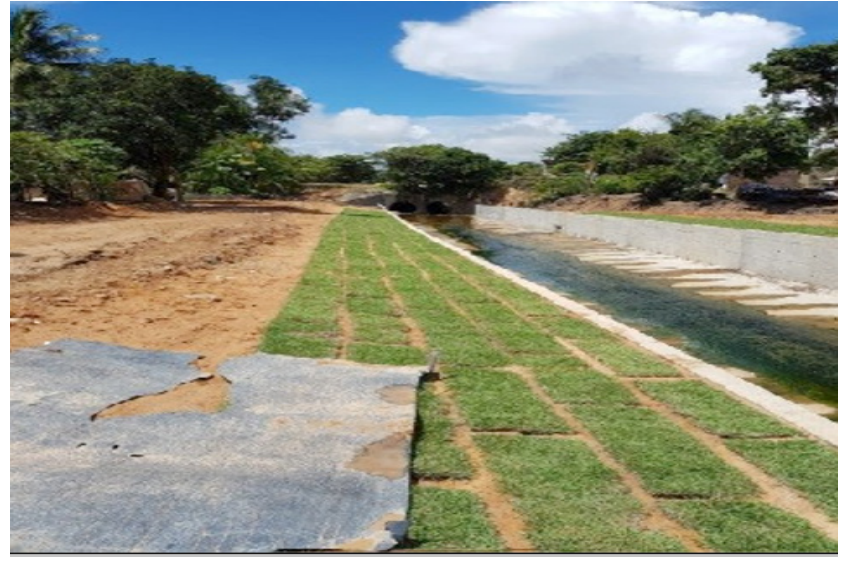

Figura 3. Trecho do Igarapé Caxangá entre a av. Nossa Sra. Da Consolata e av.Beijamin Constant Fonte: Arquivo pessoal (2018).

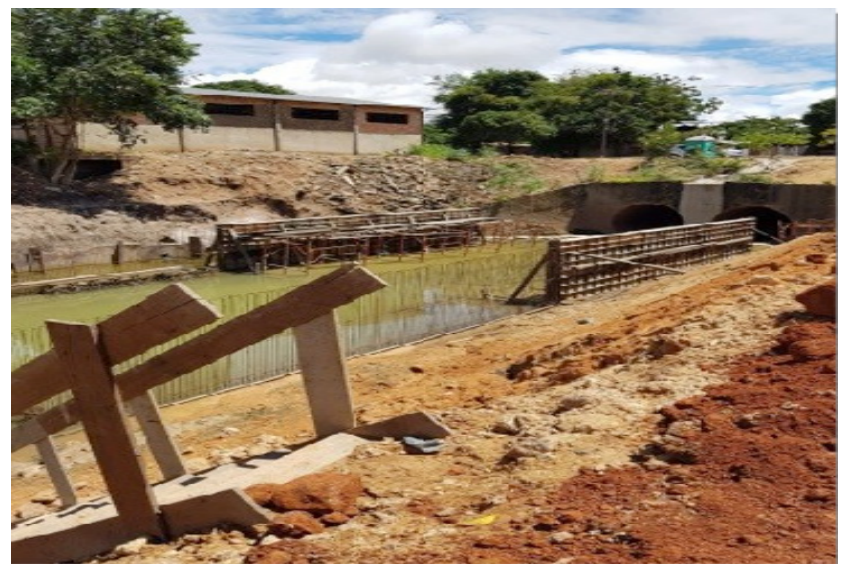

Figura 5. Trecho do Igarapé Caxangá entre a Av.Beijamin Constant e Av. Gatúlio Vargas (perspectiva interna) Fonte: Arquivo pessoal (2018).

In loco, constata-se o encaixotamento com estrutura de concreto armado do curso d'água até o trecho entre as Av. Nossa Senhora da Consolata e Av. Benjamin Constant.

Ato contínuo a seção entre Av. Benjamin Constant e a Av. Getúlio Vargas está em processo de adequação para integrar o projeto de macrodrenagem.

O trecho mais caudaloso do Caxangá, localizado entra as Av. Getúlio Vargas e Av. Sebastião Diniz, teve vários imóveis desapropriados, em razão do assentamento insalubre e insustentável. A obra de canalização deste trecho deve ocorrer nos próximos meses.

A extensão do igarapé que corta o bairro Caetano Filho, a partir da Av. Sebastião Diniz,



Figura 4. Trecho do Igarapé Caxangá entre a Av.Beijamin Constant e Av. Gatúlio vargas

Fonte: Arquivo pessoal (2018).

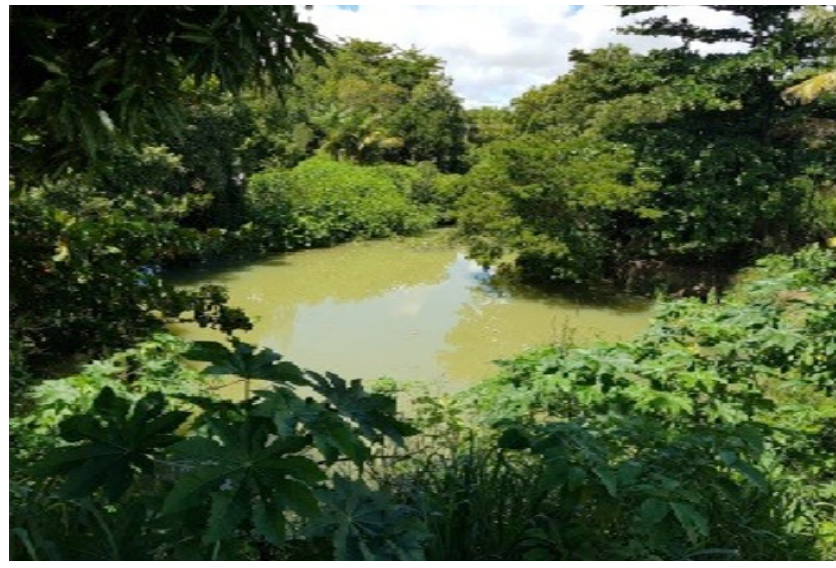

Figura 4. Trecho do Igarapé Caxangá entre a Av. Gatúlio Vargas e Av. Sebastião Diniz Fonte: Arquivo pessoal (2018).

outrossim, está completamente livre para a construção do canal de macrodrenagem, haja vista que as históricas casas de palafita que compunham o ambiente e ocupavam as margens do veio de água foram demolidas e a população remanejada.

Considerando as circunstâncias socioambientais do trecho da bacia hidrográfica do Caxangá, ora em análise, é perceptivel que todas as expectativas negativas de uma aérea ribeirinha urbana irregularmente ocupada são confirmadas com visita no local. A miserabilidade com a qual conviviam os munícipes instalados naquela região é cristalina, doravante isso, tais condições encontram-se frontalmente contrárias àquelas pensadas pelo legislador quando do fazimento da Lei 
no 6.938 de 1981.

Art 4ㅇ- - A Política Nacional do Meio Ambiente visará:

I - à compatibilização do desenvolvimento econômico-social com a preservação da qualidade do meio ambiente e do equilíbrio ecológico;

II - à definição de áreas prioritárias de ação governamental relativa à qualidade e ao equilíbrio ecológico, atendendo aos interesses da União, dos Estados, do Distrito Federal, dos Territórios e dos Municípios;

IV - ao desenvolvimento de pesquisas e de tecnologias nacionais orientadas para o uso racional de recursos ambientais;

\section{[...]}

VI - à preservação e restauração dos recursos ambientais com vistas à sua utilização racional e disponibilidade permanente, concorrendo para a manutenção do equilíbrio ecológico propício à vida;

O poder público municipal compreendeu, a despeito do projeto do Parque do Rio Branco, que a área da bacia hidrográfica do Caxangá deveria ser prioridade para ações governamentais relativas ao saneamento básico e urbanização.

Por décadas ao fio os problemas socioambientais foram marginalizados, ao passo que as intensas e sucessivas enchentes e caos social experienciado pelos moradores aumentavam. Assim sendo, pode-se afirmar que a ideal compatibilização do desenvolvimento econômico-social com a preservação da qualidade do meio ambiente e do equilíbrio ecológico não encontrava assento na realidade do Caxangá.

Não obstante a isso, o ponto central a ser atentamente observado, in casu, é a escolha do Município em utilizar a técnica de canalização do igarapé ante a outras possibilidades ecologicamente acertadas e que, realmente, restaurariam os recursos naturais ali existentes.

Destarte, vale frisar os fundamentos e objetivos elencados pela Política Nacional dos Recursos Hídricos (Lei no 9.433/ 1997):

Art. 1o A Política Nacional de Recursos Hídricos baseia-se nos seguintes fundamentos:

I - a água é um bem de domínio público;

II - a água é um recurso natural limitado, dotado de valor econômico; [...]

IV - a gestão dos recursos hídricos deve sempre proporcionar o uso múltiplo das águas; $\checkmark \quad$ - a bacia hidrográfica é a unidade territorial para implementação da Política Nacional de Recursos Hídricos e atuação do Sistema Nacional de Gerenciamento de Recursos Hídricos;

VI - a gestão dos recursos hídricos deve ser descentralizada e contar com a participação do Poder Público, dos usuários e das comunidades.

Art. 2o São objetivos da Política Nacional de Recursos Hidricos:

I - assegurar à atual e às futuras gerações a necessária disponibilidade de água, em padrões de qualidade adequados aos respectivos usos;

II - a utilização racional e integrada dos recursos hídricos, incluindo o transporte aquaviário, com vistas ao desenvolvimento sustentável;

III - a prevenção e a defesa contra eventos hidrológicos críticos de origem natural ou decorrentes do uso inadequado dos recursos naturais. IV - incentivar e promover a captação, a preservação e o aproveitamento de águas pluviais.

Em sentido contrário aos supracitados preceitos, à integração do corredor natural d'água a infraestrutura de macrodrenagem pode acarretar os mesmos danos experimentados pela canalização do Igarapé Mirandinha e outros flumens urbanos desta cidade, o que deveria servir de exemplo a não ser seguido. Transparece que obras do gênero tem por pretensão direta é o gasto dos recursos públicos e indireta o interesse da sociedade e, num plano distante, a proteção do meio ambiente.

Pontua-se que, apesar da grande promoção política da obra, os documentos essenciais ao empreendimento, como os que deveriam ser produzidos e instruir o procedi- 
mento de licenciamento ambiental, por exemplo, não estão disponíveis na rede mundial de computadores, o que cerceia uma visão mais aprofundada desta análise científica e, notadamente, da comunicação geral de todos os que são beneficiários do meio ambiente (art. 225, caput, da Constituição da República de 1988), infringindo, portanto, os princípios da informação e da participação.

Enfim, é certo que o grandioso projeto do Parque Rio Branco pode decretar a morte do igarapé Caxangá pois, canalizá-lo é materializar sua função de mero canal para águas residuais que, muita das vezes, pode ser instrumento para disposição, ilegal, do termo popularmente conhecido como esgoto.

A compatibilização das nuances aplicáveis ao desenvolvimento sustentável que é, destacadamente, uma das ferramentas impostas pelo Estatuto da Cidade (Lei no 10.257/2001) para todos os municípios do Brasil, deveria ter por referencial a internalização da responsabilidade constitucional da promoção do "adequado ordenamento territorial, mediante planejamento e controle do uso, do parcelamento e da ocupação do solo urbano" (art. 30, VIII), situação esta que envolve qualquer empreendimento público.

As consequências socioambientais, portanto, ao longo do tempo, com a implantação da macrodrenagem no igarapé Caxangá, valendo-se do que já ocorreu no igarapé Mirandinha, podem ser esperadas como negativas, prejudiciais e nocivas e, muito das vezes, irreversiveis.

Um fiel e adequado acompanhamento do licenciamento ambiental, decerto, poderia ensejar uma melhor resposta aos interesses metaindividuais preteridos, isto sem olvidar da ação de medidas compensatórias e mitigatórias dos efeitos lesivos do empreendimento a curto, médio e longo prazos.

\section{CONSIDERAÇÕES FINAIS}

Apar das consequências certas e percep- tíveis da implantação de empreendimento de macrodrenagem, esteja ou não inserido em um contexto maior como é o projeto do Parque do Rio Branco, observa-se do ordenamento jurídico a existência de princípios que deveriam ser cumpridos, antes, durante e após a execução das obras, como o do ambiente ecologicamente equilibrado, o do desenvolvimento sustentável e o da sadia qualidade de vida reconhecidos como direitos humanos fundamentais.

A perspectiva da incidência destas obrigações cogentes são imanentes à natureza da matéria em estudo que cobra uma visão interdisciplinar e holística a açambarcar não só o direito, mas toda e qualquer área do conhecimento científico que possa, de algum modo, contribuir para cumprir tais regras em nome da sociedade.

Para compreender esta dinâmica, sua constituição física e humana e implicações que tem por condão modificar e produzir o espaço urbano, deve ser auxiliada de forma conglobante e integral por mecanismos de ordem técnica e científica, razão pela qual as instituições de pesquisa podem exercer papel fundamental na construção de resoluções que minimizem ou, no melhor das hipóteses, evitem os gravames ambientais, sociais, culturais, econômicos, políticos e urbanísticos.

Afinal de contas, os maiores prejudicados com eventuais problemas decorrentes da implantação do empreendimento é, de fato e de direito, a coletividade, com destaque para aqueles que utilizam o espaço que está sendo alterado radicalmente pelo poder público municipal.

É imprescindivel que a administração pública perceba os recursos naturais como meio de prevenção de danos outros, como os sociais, urbanísticos, culturais e até econômicos, isto valendo-se dos predicados de conservação (uso racional) e, nalguns casos, da própria preservação que incute maior proteção. Tal razão de ser é devido a constatação de que, em grande parte, os referidos danos 
são meros reflexos da atuação humana desorganizada, ecologicamente inconsciente e nitidamente insustentável.

Sendo assim, com vistas à essencial posição que guardam os princípios da Educação ambiental, da Informação e da Participação Comunitária na busca pelo Desenvolvimento Sustentável, é que se propõe, antes de tudo, a existência de atuação estatal no sentido de orientação específica aos moradores dos locais circundantes às áreas de maior importância ambiental a fim de viabilizar a realização de obras não-estruturais que sejam abalizadas técnica e cientificamente.

E, a partir desse ponto, é real a necessidade de se envidar esforços no sentido da implementação de padrões de controle mais eficazes e que busquem uma visão concreta de desenvolvimento sustentável no ambiente urbano, inclusive embasada no cumprimento fidedigno dos pressupostos normativos aplicáveis em nível federal, estadual e, sobretudo, municipal.

É desse modo que a prevenção tornasse a orientação essencial para o atingimento do fim do Estado que é a promoção do bem-estar social que leve em consideração a proteção do meio ambiente como elemento impostergável para a própria sobrevivência.

Singular providência para o atingimento deste ideário, assim, envolve uma reformulação e reflexão detida sobre a política pública da realização das obras de macrodrenagem dos cursos d’água e seu paralelo com os superiores interesses das presentes e futuras gerações e respeito para com a biodiversidade existente nestes espaços extremamente sensiveis a ação humana.

\section{REFERÊNCIAS}

ANDRADE. J. SOS Igarapé Caxangá - Boa Vista (RR) - Prefeitura fará a recuperação do Igarapé. Blog SOS Rios do Brasil, 2011. Disponível em: < http://sosriosdobrasil.blogspot. com/2011/07/sos-igarape-caxanga-boa-vista- -rr.html >. Acesso em: 31 mai. 2018.

ARAÚJO JÚNIOR, A. C. R.. Bacias hidrográficas e o planejamento ambiental da cidade de Boa Vista - RR. In: XVIII Encontro Nacional de Geógrafos, 2016, São Luis. Anais do XVIII Encontro Nacional de Geógrafos. São Paulo: AGB-SP, 2016. Disponivel em: <http://www.eng2016.agb. org.br/resources/anais/7/1466184884_ARQUIVO_ARTIGO_BH.pdf >. Acesso em: 01 jun 2018.

Domínio sobre a natureza e a (des) construção de áreas de risco à inundação na cidade de Boa Vista - Roraima. In: Simpósio Nacional de Geografia Urbana, 2015, Fortaleza. Anais do XIV Simpósio Nacional de Geografia Urbana, 2015. Disponivel em: < https://drive. google.com/file/d/0B_FJH8ikGCJtRXBwQ0lzZDRUYWs/view >. Acesso em: 01 jun 2018.

ARAÚJO JÚNIOR, A. C. R.; TAVARES JÚNIOR, S. S.. Expansão urbana e fatores de risco à inundação em Boa Vista - RR. Revista Ra'e Ga Espaço Geográfico em Análise, v. 44, p. 139-153, 201. Disponível em: < https://revistas.ufpr.br/raega/article/download/49680/35359 >. Acesso em: 01 jun. 2018.

Uso e cobertura do solo para o planejamento urbano, Boa Vista, Roraima, Brasil. Boletim Goiano de Geografia, vol. 37, num. 1, p. 36-55, enero-abril, 2017; Universidade Federal de Goiás, Goiás, Brasil. Disponível em: < http:// www.redalyc.org/pdf/3371/337150414004.pdf >. Acesso em: 01 jun. 2018.

Área próxima ao Igarapé Caxangá está virando lixão a céu aberto. Portal da Folha De Boa Vista - Folha Web, 2017. Disponível em: < http:// folhabv.com.br/noticia/- Area-proxima-ao-igarape-Caxanga-esta-virando-lixao-a-ceu-aberto-/28755 >. Acesso em: 31 mai. 2018.

AVLIS, K.; NORMANDO, A. Prefeitura de Boa Vista executa a segunda etapa da obra do Igarapé Caxangá. Portal Imediato Online, 2018. 
Disponivel em: < http://imediatoonline.com/ post/prefeitura-de-boa-vista-esta-executando-a-segunda- etapa-da-obra-do-igarape-caxanga >. Acesso em: 31 mai. 2018.

BOA VISTA. Plano Diretor do Município de Boa Vista. Lei Complementar no 924, de 28 de Novembro de 2006. Dispões sobre o plano diretor estratégico e participativo de Boa Vista e dá outras providências. Disponivel em: < https://www.boavista.rr.gov.br/prefeitura-legislacao-municipal >.

BRASIL. Constituição da República Federativa do Brasil: promulgada em 05 de outubro de 1988.

Convênio para execução de obras de macrodrenagem urbana do Caxangá. Portal Federal da Transparência. Disponível em: <http://www.portaldatransparencia.gov. $\mathrm{br} /$ convenios/DetalhaConvenio.asp? CodConvenio $=688166 \& \mathrm{TipoConsulta}=0 \& U \mathrm{~F}=\mathrm{rr} \&$ Cod Municipio $=301 \&$ CodOrgao $=\&$ Pa gina $=1 \&$ Perio do >. Acesso em: 02 jun. 2018.

Lei no 6.938 de 31 de agosto de 1981. Disponivel em: <http:// www.planalto.gov.br/ccivil_03/leis/L6938.htm >. Acesso em: 18 mai. 2018.

Lei no 9.433 de 08 de janeiro 1997. Disponivel em: <http://www. planalto.gov.br/ccivil_03/Leis/19433.htm >. Acesso em: 02 jun. 2018.

Lei $\mathrm{n}^{\circ} \mathbf{9 . 6 0 5}$, de 12 de fevereiro de 1998. Sanções Penais e Administrativas derivadas de condutas e atividades lesivas ao meio ambiente. Disponivel em:<http://www.planalto. gov.br/ccivil_03/Leis/L9605.htm>. Acesso em: 11 jul. 2018.

Lei no 10.257, de 10 de julho de 2001. Regulamenta os arts. 182 e 183 da Constituição Federal(Estatuto da Cidade). D i s - ponivel em: <http://www.planalto.gov. br/ccivil_03/leis/LEIS_2001/L10257.htm>. Acesso em: 10 jul. 2018.

Lei no 12.651, de 25 de maio de 2012. Dispõe sobre a proteção da vegetação nativa. Disponível em: <http://www2.camara.leg.br/legin/fed/ lei/2012/lei- 12651-25-maio-2012-613076-publicacaooriginal-136199-pl.html>. Acesso em: 11 jul. 2018.

Lei Complementar no 140 de 08 de dezembro de 2011. Disponivel em: <http:/ / www.planalto. gov.br/ccivil_03/leis/lcp/lcp140.htm >. Acesso em: 18 mai. 2018.

Resolução no 237 de 19 de dezembro de 1997. Disponivel em: <http://www.mma.gov. $\mathrm{br} /$ port/conama/res/res97/res23797.html >. Acesso em: 18 mai. 2018.

CAVAlCANTE, F. Parque do Rio Branco: Prefeitura inicia obras de canalização do Igarapé Caxangá. Portal Roraima em Foco, 2018. Disponivel em: <https://roraimaemfoco.com/2018/ parque-do-rio-branco-prefeitura-inicia-obras-de- canalizacao-do-igarape-caxanga/ >. Acesso em: 31 mai. 2018.

Contratação de empresa especializada em obras e serviços de engenharia, para execução de obra no canal de macrodrenagem do Igarapé Caxangá - (2a etapa) - Boa Vista/RR, divididos em 2 (dois) lotes - LOTE I. Portal da Transparência do Município de Boa Vista. Disponivel em:<http://transparencia.boavista.rr.gov.br/portal/cpl_ler.php? $x=0$ DYw >. Acesso em: 31 mai. 2018.

Contratação de empresa especializada em obras e serviços de engenharia, para execução de obra no canal de macrodrenagem do Igarapé Caxangá - (2a etapa) - Boa Vista/RR, divididos em 2 (dois) lotes - LOTE II. Portal da Transparência do Município de Boa Vista. Disponivel em: < http://transparencia. 
boavista.rr.gov.br/portal/cpl_ler.php?x=ODQy >. Acesso em: 01 jun. 2018.

COSTA, R. J. T. Direito Ambiental: para concursos e exame de ordem. Curitiba: Juruá, 2014.

DOS SANTOS, A. C.; CAVALCANTI, A. P. B. Análise do controle ambiental realizado no Igarapé Mirandinha, Boa Vista - RR, 1999. Caminhos da Geografia (revista online), v. 7, n. 20, p. 53 - 61; Uberlândia, 2007. Disponivel em: <http:// www.seer.ufu.br/index.php/caminhosdegeografia/article/download/15520/8788

> Acesso em: 31 mai. 2018.

INSTITUTO BRASILEIRO DE GEOGRAFIA E ESTATÍSTICA (IBGE). Disponivel em: <https://cidades.ibge.gov.br/brasil/rr/boa-vista/panorama>. Acesso em: 10 jul. 2018.

Igarapé Mirandinha: À pedido do MPE obras foram paralisadas e licenças anuladas. Página do Ministério Público do Estado de Roraima no Portal JusBrasil, 2010. Disponivel em: <https:// mp-rr.jusbrasil.com.br/noticias/2198970/igarape-mirandinha- a-pedido-do-mpe-obras-foram-paralisadas-e-licencas-anuladas

Acesso em: 31 mai. 2018.

Igarapé Mirandinha: MPRR pede análise de água. Página do Ministério Público do Estado de Roraima no Portal JusBrasil, 2012. Disponível em: <https://mp- rr.jusbrasil.com.br/noticias/3005576/igarape-mirandinha-mprr-pede-analise-de-agua>. Acesso em 31 mai. 2018.

Infraestrutura: Obras do Parque do Rio Branco são iniciadas em Boa Vista. Portal da

Prefeitura de Boa Vista, 2018. D i s ponivel em: <https://www.boavista. rr.gov.br/noticias/2018/02/infraestrutura-obras-do-parque-do- rio-branco-sao-iniciadas-em-boa-vista >. Acesso em: 31 jun. 2018.

Moradores reclamam de poluição e mau cheiro em igarapé de Boa Vista. Portal G1 Rorai- ma, Rede Amazônica, 2015. Disponível em:<http://g1.globo.com/rr/roraima/noticia/2015/09/moradores-reclamam-de-poluicao-e- mau-cheiro-em-igarape-de-boa-vista. html >. Acesso em: 31 mai. 2018.

Orientações básicas para drenagem urbana. Belo Horizonte: Fundação Estadual do Meio Ambiente, 2006.

Parque do Rio Branco - Iniciadas obras de canalização do Igarapé Caxangá. Portal da

Prefeitura de Boa Vista, 2018. D i s ponivel em: <https://www.boavista. rr.gov.br/noticias/2018/04/parque-do-rio-branco-iniciadas- obras-de-canalizacao-do-igarape-caxanga >. Acesso em: 31 jun. 2018.

Parque do Rio Branco: Prefeita Teresa Surita anuncia projeto de revitalização do Caetano Filho. Portal da Prefeitura de Boa Vista, 2017. Disponivel em: <https://www. boavista.rr.gov.br/noticias/2017/07/parque-do-rio-branco-prefeita- teresa-surita-anuncia-projeto-de-revitalizacao-do-caetano-filho >. Acesso em: 31 mai 2018.

Plano Diretor de drenagem para a bacia do Rio Iguaçu na região metropolitana de Curitiba. Governo do Estado do Paraná, 2002.

POERSCHKE, N. Relatório sobre as condições ambientais dos igarapés de Boa Vista - RR. Disponivel em: <http://www. ebah.com.br/content/ABAAAesb8AG/estudo-das-condicoes-ambientais- dos-igarapes-boa-vista-rr?part=3 >. Acesso em: 01 jun. 2018.

Prefeitura investirá $R \$ 43$ mi na segunda etapa de obras no igarapé Caxangá. Portal Brasil Norte Comunicação, 2017. Disponivel em: <http://roraima.bncamazonia.com.br/poder/prefeitura-investira-r-43-mi-na-segundaetapa-de-obras-no-igarape-caxanga/ >. Acesso em: 31 mai. 2018. 
RAMOS, W. CAXANGÁ - MPRR dá 180 dias para CAER substituir motores da Estação

Elevatória. Portal Fato Real, 2011. D i s ponivel em: <http://www.fatoreal. blog.br/meio-ambiente/caxanga-mprr-da-180-dias-para-caer- substituir-motores-da-estacao-elevatoria/ >. Acesso em: 31 mai. 2018.

RODRIGUES, A. S.; MONTEIRO, E. A.; SILVA, N. R.; SILVA, H. F.; SANTOS E. L.; FURTADO, E. F.. Aplicação de protocolos de avaliação rápida da diversidade de habitat do Igarapé Caxangá, município de Boa Vista - RR. Reunião Regional da SBPC em Boa Vista. Disponível em: <http://www.sbpcnet.org.br/livro/boavista/resumos/1454.htm >. Acesso em: 31 mai. 2018.

RORAIMA. Lei Complementar no 7 de 26 de agosto de 1994. Disponivel em: <https:// www.legisweb.com.br/legislacao/ ?id=161311 >. Acesso em: 21 abr. 2018.

SCHAEFER, C. E. R. Landscape Ecology and Land Use Patterns in Northeast Roraima, Brazil. Royal Holloway, University of London, CEDAR Research Papers: 11:1-24, 1994.

SILVA, R. F. T. Manual de Direito Ambiental. 6 ed. rev. ampl. e atual. Salvador. JusPODVIM, 2016.

SUÉCIA. Declaração das Nações Unidas sobre Meio Ambiente Humano de 1972. D i s ponivel em: <https://www.apambiente. pt/_zdata/Politicas/DesenvolvimentoSustentavel/1972_Dec laracao_Estocolmo.pdf >. Acesso em: 21 abr. 2018.

TONELLO, M. F.; FERREIRA, E. S.; RODRIGUES, I. O. M.; SOUZA, V.. Situação ambiental do Igarapé Mirandinha (Canalização). Revista Acta Geográfica, ano II, nº 4, jul./dez. de 2008. p. 41- 53. Disponível em: <https://revista.ufrr.br/actageo/article/ download/195/373 >. Acesso em: 31 mai. 2018.

VALE JÚNIOR, J. F. Pedogênese e alterações dos solos sob mane- jo itinerante, em áreas de rochas vulcânicas ácidas e básicas, no nordeste de Roraima. 2000. 185 f. Tese (Doutorado) - Universidade Federal de Viçosa, Viçosa, MG, 2000.

VALE JÚNIOR, J. F.; SOUSA, M. I. L.; NASCIMENTO, P. P. R. R. Solos e Ambientes em Roraima. IN: CPRM, 2014. Geodiversidade do Estado de Roraima. Manaus, 2014.

VELASQUE, W. A importância do corredor egológico do Igarapé Mirandinha para a sadia qualidade de vida no município de Boa Vista. - Boa Vista, 2012. 227p.; Disponivel em: <http://www.necar.ufr.br/index.php? option=com_phocadownload\&view=category\&download=188:dissertao-warner- velasque-ribeiro\&id=38:minter-direito-ambiental\&Itemid=377 >. Acesso em: 31 mai. 2018. 